\title{
New members
}

Antenucci, John, OUCOM '85; 5578 Concord Hill Dr, Columbus, $\mathrm{OH}$ 43213-3503

Bajo, Joseph T, CCOM '88; 444 W Fullerton, Chicago, IL 60614

Bell, Michael M, CCOM '79; PO Box 950, Poughkeepsie, NY 126020950

Byers, James, MSUCOM '78; 412 Lake Ave, Spring Lake, MI 49456-2137

Byrnes, Richard D, PCOM '72; 650 E Broad St, Souderton, PA 18964

Calvin, Glen D, KCOM '67; 115 W Locust, Union, MO 63084-1797

Carr, Alan H, UHSCOM '81; Box 476, San Antonio, FL 335760476

Casey, Rick, UHSCOM '82; Box 301, El Dorado Springs, MO 647440301

Cunicella, Kathleen M, PCOM '85; PO Box 997, Inverness, FL 32651-0997

Dunnigan, Michael P, CCOM ' 87; 35 Lake Ave, Lancaster, NY 140862608

Englehart, John D, KCOM '61; Box 128, Lutesville, MO 63762-0128

Greear, Randall Alan, WVSOM '80; 5609 Pine Barren Dr, Morristown, TN 37814

Izbicki, Robert J, UHSCOM '57; 1545 W 38 th St, Erie, PA 16508 2345

Jonesco, John M, CCOM '79; 319 W Lorain St, Oberlin, OH 44074

King, Edward W, TCOM '85; 6321 Fairhill St, Philadelphia, PA 19126-3846
Kovachevich, Thomas, CCOM '69; 9 White St, New York, NY 10013

Kowalski, Marie L, CCOM '82; 6836 N Moselle Ave, Chicago, IL 60646-1034

Latos, Sheldon K, KCOM '82; 2826 Saint Charles Ave, New Orleans, LA 70115-4420

Levin, Mortimer, UOMHS ' $50 ; 1747$ Shore Club, St Clair Shores, MI 48080

Lewis, Adolphus R, TCOM '86; 4732 East Lancaster, Ft Worth, TX 76103-3836

Marsh, Ian A, KCOM '58; 2603 Bridgeport Way W, Tacoma, WA 98466-4724

Meehan, John J, UHSCOM '76; 5206 Wimbledon Ct, Arlington, TX 76017

Milazzo, Leah Marie, UHSCOM '83; 6700 N Oracle Rd, Tucson, AZ 85704-7732

Nestola, Joseph F, NYCOM '85; 147 28 Jewel Ave, Flushing, NY 11367-1734

Nurick, Kim B, UOMHS '87; 3526 Calumet St, Philadelphia, PA 19129

Orr, Dennis P, UOMHS '75; 10850 Mahoning Ave, North Jackson, OH 44451-9751

Papp, Charles A, MSUCOM '86; W 8052 Lake Antoine Rd S, Iron Mountain, MI 49801-9601

Pascual, Alfred, COMP '84; 10637 Rathburn Ave, Northridge, CA 91326-3126

Patton, Peter J, PCOM '89; 100 Cliften Ct, Ponte Verdra, FL 32082
Puryear, Billy H, UHSCOM '68; 4010 E Belknap St, Ft Worth, TX 76111-6691

Rosenfeld, Andrew, UMDNJ/SOM ' 82 ; 4458 Apple Valley Ln, West Bloomfield, MI 48323

Rosman, Paul M, UHSCOM '69; 8554 Red Oak Dr NE, Warren, OH 44484-1630

Spanos, Kevin, WVSOM '82; PO Box 436, Bruceton Mills, WV 26525

Stanton, James Doak, TCOM '84; 606 Fort Baker, Sausalito, CA 94965-2604

Thompson, Ted B, UHSCOM ' 57 ; 3414 Avenue "F," Bay City, TX 77414-7110

Varlotta, David, NYCOM '83; 5108 E Longboat Blvd, Tampa, FL $33615-4230$

Vogler, Charles D, TCOM '75; 1275 Adolph Shores, Coldwater, MI 49036

Webb, Cindy Renee, OUCOM '87; 3015 Van Aken Blvd, Shaker Heights, OH 44120-2816

Willyard, David C, UOMHS '81; Rt 7 Johnson Rd \& 150, Columbia City, IN 46725-9807

Young, Gardner D, SEUHSCOM '88; 75 NW 118th St, Miami, FL $33168-4428$

Zacher, Millicent SG, PCOM '79; 100 Laurel Ave, Cheltenham, PA 19012-2044

Zirille, Michael J, OUCOM '85; 179 Myrtle Ave, Gallipolis, $\mathrm{OH}$ 45631

Zubres, Mark D, CCOM '77; 5155 Raytown Rd, Kansas City, MO 64133 


\section{POSTHERPETIC NEURALGIA There Are Many Words To Describe The Pain.}

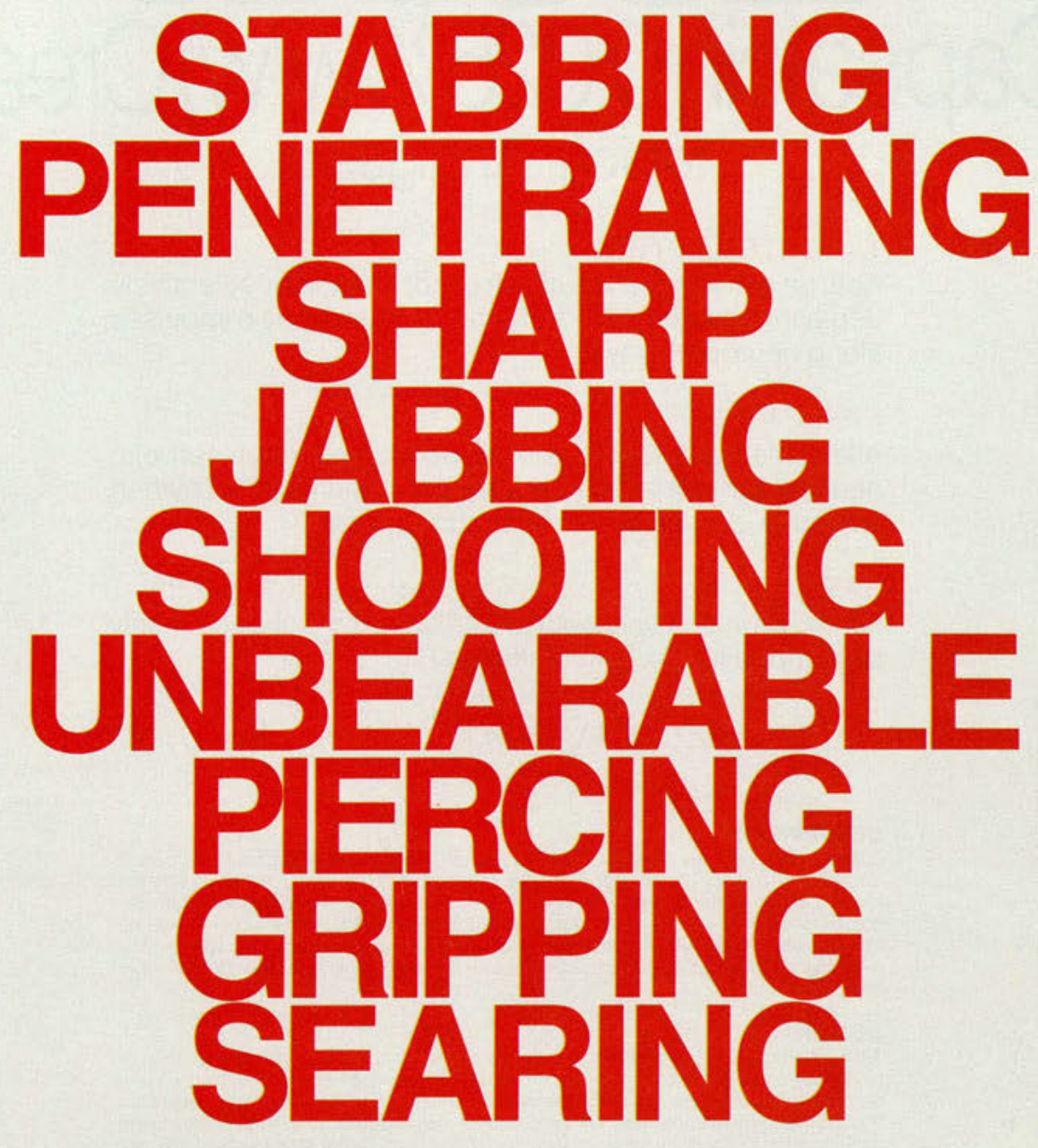

\section{And One For Treating It.}

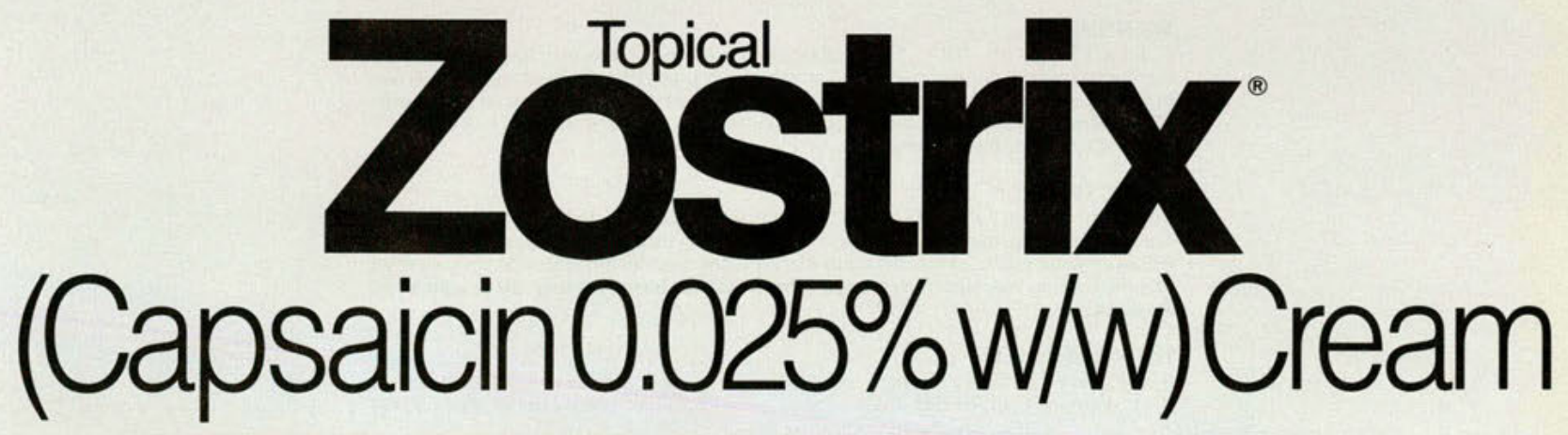

When patients describe the "hurt" of postherpetic neuralgia (PHN), they use a wide range of words to describea pain that is often intractableand difficult to treat. Zostrix ${ }^{\$}$ (Capsaicin $0.025 \%$ w/w) Cream providesan effective topical treatment that alleviates intense pain in most $\mathrm{PHN}$ patients. 


\section{Zostrix \\ (Capsaicin $0.025 \%$ w/w) Cream Topical Analgesic}

TARGETED ACTION

Acts on sensory nerves at site of application by selectively depleting substance $\mathrm{P}$, a chemomediator of pain impulses along neuropathways.

\section{EFFECTIVE}

Alleviates the intense pain associated with postherpetic neuralgia in most patients. May also benefit patients when added to existing systemic drug regimens.

\section{SAFE}

No known interactions with systemic medications commonly prescribed for geriatric patients.

\section{Topical Zostrix Works Where It Hurts}

\section{DESCRIPTION}

Zostrix Cream contains capsaicin, $0.025 \%$ w/w, in an emollient base containing benzyl alcohol, cetyl alcohol, glyceryl monostearate, isopropyl myristate, polyoxyethylene stearate blend, purified water, sorbitol solution and white petrolatum. Capsaicin is a naturally occurring substance derived from plants of the Solanaceae family with the chemical name trans-8-methyl- $\mathrm{N}$-vanillyl-6-nonenamide. Capsaicin is a white crystalline powder with a molecular weight of 305.4. It is practically insoluble in water but very soluble in alcohol, ether and chloroform.

\section{ACTION}

Although the precise mechanism of action of capsaicin is not fully understood, current evidence suggests that capsaicin renders skin and joints insensitive to pain by depleting and preventing reaccumulation of substance $P$ in peripheral sensory neurons. Substance $P$ is thought to be the principal chemomediator of pain impulses from the periphery to the central nervous system. In addition, substance $P$ has been shown to be released into joint tissues and activate inflammatory mediators involved with the pathogenesis of rheumatoid arthritis.

\section{INDICATION}

Zostrix is indicated for the temporary relief of peripheral neuralgias such as the pain following shingles (herpes zoster). Zostrix is also indicated for the temporary relief of the pain associated with rheumatoid arthritis and osteoarthritis.

\section{WARNINGS}

FOR EXTERNAL USE ONLY. Avoid contact with eyes and broken or irritated skin. Do not bandage tightly. If condition worsens, or does not improve after 28 days, discontinue use of this product and consult your physician. Keep this and all drugs out of the reach of children. In case of accidental ingestion, seek professional assistance or contact a Poison Control Center immediately.

\section{DIRECTIONS}

Adults and children 2 years of age and older: Apply Zostrix to affected area 3 to 4 times daily. Transient burning may occur upon application, but usually disappears in 72 hours. Application schedules of less than 3 to 4 times a day may not provide optimum pain relief and the burning sensation may persist. Wash hands immediately after applying Zostrix.

\section{HOW SUPPLIED}

\section{Marketed by GENDERM ${ }^{\circledR}$ Corporation \\ Northbrook, IL 60062}

